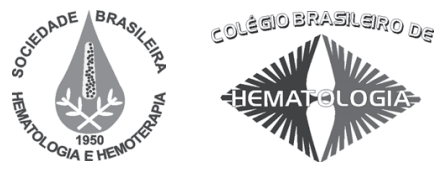

\title{
Chronic myelogenous leukemia: the present and the future of the TKI therapy
}

\author{
Leucemia mieloide crônica: o presente e o futuro dos inibidores de tirosino quinase
}

Giuseppe Saglio

Carmen Fava

\begin{abstract}
Impressive response rates and the good tolerability have allowed imatinib to become the gold standard frontline therapy for all CML patients in the early chronic phase. Optimal outcomes are attained with more than two thirds of the CML cases treated with standard dose imatinib (400 mg daily). Criteria to establish failure and suboptimal responses to imatinib have been defined. Treatment guidelines have also suggested imatinib dose escalation based on clinical assessments of disease response. However, despite all the effort to optimize therapy with imatinib, cases of real resistance exist. For imatinib resistant and intolerant cases, second generation powerful tyrosine kinase inhibitors (TKIs) have been developed and registered. Sequential kinase inhibitor therapy is used to overcome resistance however, a future strategy might be a combination therapy with different $A B L$ kinase inhibitors in the same therapeutic scheme, used sequentially or simultaneousl. Rev. Bras. Hematol. Hemoter. 2009;31(Supl. 2):57-60.
\end{abstract}

Key words: Chronic myeloid leukemia; TKi inhibitor; resistence and intolerance.

\section{Introduction}

Impressive response rates and the good tolerability have allowed imatinib to become the gold standard frontline therapy for all CML patients in the early chronic phase. This conclusion has been mainly reached through the results of the IRIS trial. ${ }^{1}$ In fact, as shown in a recently presented revision of the data of this study ${ }^{2}$ after seven years of followup and for the trial arm in which the patients were assigned to receive imatinib ( $400 \mathrm{mg}$ daily), $60 \%$ of patients are still on treatment and almost all of them in stable complete cytogenetic remission (CCyR). ${ }^{2}$ The remaining patients $(40 \%)$ discontinued treatment because of inadequate response, loss of response, adverse events or protocol violation. Altogether, the overall survival (OS) after seven years is $88 \%$ and only $5 \%$ of patients have died due to CML-related causes. These data have been deduced so far from a single study and await definitive confirmation from other important ongoing trials, but there is a general consensus about the optimal outcome of more than two thirds of the CML cases treated with standard dose imatinib (400 mg daily). ${ }^{2}$
Criteria to establish failure and suboptimal responses to imatinib have been defined. ${ }^{3}$ In particular, hematologic resistance (rare, $2 \%-3 \%$ of all cases) at 3-6 months, lack of any degree of cytogenetic response at 6 months, lack of a major cytogenetic response at 12 months (> 35\% Ph-positive metaphases) and absence of a complete cytogenetic response at 18 months, are all considered failures and other treatment strategies are justified in these cases as the residual probability of achieving optimal response in such patients is low. ${ }^{3}$ Primary failure occurs in approximately $15 \%$ of all patients, but in the "failure" group we must also include those patients (14\% in the IRIS) who initially achieve the responses expected at the established time-points, but subsequently lose them. In some of these cases (6-7\%) progression to accelerated or blast phase of CML is observed. Failure must be distinguished from what has been defined as "suboptimal response", an intermediate situation between optimal response and failure, in which the response is slower than expected, but there is still a substantial chance for the patient to achieve the awaited response at a later time point. ${ }^{3}$ A revision of these guidelines will probably be published in 2009 , and probably it will contain more stringent criteria in the definition of optimal response,

Department of Clinical and Biological Sciences, University of Turin, San Luigi Gonzaga Hospitao, Torino, Italy.

Correspondence: Giuseppe Saglio

Department of Clinical and Biological Sciences

University of Turin, San Luigi Gonzaga Hospital

10043 - Orbassano-Torino, Italy

E-mail:saglio@csi.it 
as now second generation TKIs are registered and available for suboptimal responders and failure patients. In some cases, suboptimal responses and also failures may simply be due to a lower imatinib plasma level than is explained due to, for example, poor compliance to daily oral therapy, drug-drug interactions, interaction with food or concomitant diseases. ${ }^{4}$ In other cases, genetic polymorphisms of the genes involved in the cellular drug influx-efflux processes may be responsible for insufficient imatinib concentrations within the cells. ${ }^{5}$ A correlation of imatinib trough plasma concentrations (Cmin) with clinical responses, event-free survival (EFS), and adverse events (AEs) has recently been described using 5-year follow-up data from the IRIS study patients randomized to first-line imatinib. ${ }^{6}$ The cumulative estimated complete cytogenetic response (CCyR) and major molecular response (MMR) rates were shown to be different between the quartile categories of imatinib trough levels. Patients with a high imatinib exposure showed better CCyR and MMR rates and EFS. An exploratory analysis has shown that imatinib trough levels were predictive of higher CCyR independently of Sokal risk group. Patient demographics including age, gender, and body weight or body surface area have little impact on imatinib pharmacokinetic (PK) exposure compared with inter-patient variability. Maintaining plasma trough levels at or above the mean population concentration of approximately $1000 \mathrm{ng} / \mathrm{mL}$ may be important for achieving improved CCyR and MMR rates. ${ }^{6}$

Treatment guidelines have also suggested imatinib dose escalation based on clinical assessments of disease response. ${ }^{3}$ Recently, response and survival data were analyzed in a cohort of patients with newly diagnosed CML$\mathrm{CP}$ enrolled on the IRIS trial, who began treatment with imatinib (400 mg daily) and subsequently underwent dose escalation to either 600 or $800 \mathrm{mg}$ daily. ${ }^{7}$ Reasons for dose escalation were evaluated retrospectively based on two sets of criteria: the IRIS protocol-defined criteria and European LeukemiaNet (ELN) recommendations. ${ }^{3}$ Among all 106 patients who underwent dose escalation, freedom from progression to accelerated or blast phase and overall survival were $89 \%$ and $84 \%$ at 3 years after dose increase, respectively. ${ }^{7}$ This analysis supports imatinib dose escalation as an appropriate initial option for patients with CML-CP who do not achieve clinical response milestones or whose disease appears to be progressing. A higher dose of imatinib ( $800 \mathrm{mg}$ per day) has been suggested to accelerate to achievement and to improve the rates of cytogenetic and molecular responses. ${ }^{8}$ If high dose imatinib is really beneficial for all CML patients in early chronic phase or at least for some specific risk subgroups of patients is still a matter for investigation and important answers on this topic will soon become available. ${ }^{9,10}$

However, despite all the effort to optimize therapy with imatinib, cases of real resistance exist. The most common mechanisms of resistance to imatinib include: (i) BCR-ABL kinase domain mutations; (ii) BCR-ABL over-expression; (iii) clonal evolution with activation of additional transformation pathways. ${ }^{11,12}$

The most studied mechanism of resistance to imatinib therapy is the development of point mutations within the kinase domain of BCR-ABL. The frequency of BCR-ABL mutations in imatinib resistant patients ranges from $40-90 \%$ depending on the CML phase and on the methodology used for detection. ${ }^{13}$ Depending on the region where they are located, mutations can actually act by interrupting critical contact points between the drug and the BCR/ABL protein or by inducing a conformational change to which imatinib is unable to bind. At present, more than 100 different BCR/ ABL mutations have been identified in patients with imatinib-resistant CML. ${ }^{13}$ Many of these are relatively rare, whereas the most common, which account for $60 \%-70 \%$ of all the mutations, affect Gly250, Tyr253, Glu255, Thr315, Met351 and Phe 359 residues. ${ }^{13,14}$ Mutations also differ from each other for the kind of resistance they can determine: some mutant clones are completely resistant $(\mathrm{Y} 253 \mathrm{~F} / \mathrm{H}$, E255K, T315I), others only partially (M244V, F317L, Met351T). In the latter case, the sensitivity can be restored by simply increasing the imatinib dose. The mutations with a greater level of resistance fall inside the ATP binding site of the KD domain, a highly conserved region responsible for phosphate binding and known as the phosphate-binding loop (P-loop) (a.a. 248-256). ${ }^{13}$

For the imatinib resistant and intolerant cases, second generation powerful tyrosine kinase inhibitors (TKIs) have been developed and registered. ${ }^{14}$

Dasatinib (Sprycel®, Bristol-Myers Squibb, New York, NY), a multi-kinase inhibitor with an in vitro potency against unmutated BCR-ABL 325 times greater than imatinib, inhibits most known BCR-ABL mutants with the exception of T315I. ${ }^{15}$ Dasatinib also inhibits other tyrosine kinases, including the Src Family Kinases (SFK) ${ }^{16}$ The SFK, such as Lyn, may play an important role in the development of resistance to imatinib. ${ }^{17,18}$ Orally administered dasatinib has shown consistent clinical benefits for patients with CML$\mathrm{CP}, \mathrm{CML}$ in accelerated phase (CML-AP), CML-BP or $\mathrm{Ph}+$ acute lymphoblastic leukemia $(\mathrm{Ph}+\mathrm{ALL})$ resistant or intolerant to imatinib and is approved for use at a dosing regimen of $70 \mathrm{mg}$ twice daily. ${ }^{19-22} \mathrm{~A}$ phase 3 dose-optimization study in patients with imatinib-resistant or -intolerant CML-CP demonstrated that $100 \mathrm{mg}$ dasatinib, once daily, had similar efficacy and improved tolerability relative to $70 \mathrm{mg}$ twice daily, ${ }^{23}$ and as a result, the recommended initial dasatinib dose for these patients is currently $100 \mathrm{mg}$ once daily. For instance, the fact that dasatinib acts potently on many members of the SFKs and also on KIT, PDGFR and Ephrin Receptor (EPHA2) tyrosine kinases, which are directly implicated in many biological processes, may provide the physiological explanation for some of the toxicities observed, such as pleural effusion and myelosuppression. ${ }^{19-22}$ 
Nilotinib (Tasigna ${ }^{\circledR}$; Novartis Pharmaceuticals, East Hanover, NJ, USA) is a second-generation tyrosine kinase inhibitor (TKI) designed with enhanced selectivity and potency for BCR-ABL compared to that of imatinib. In vitro studies demonstrate that nilotinib is 20 - to 50 -fold more potent than imatinib. ${ }^{24-26}$ Nilotinib exhibits in vitro inhibitory activity against the majority of mutant BCR-ABL kinases that may be present following imatinib resistance, with the exception of the T315I mutation. ${ }^{24-26}$ Nilotinib is approved for the treatment of patients with $\mathrm{Ph}+\mathrm{CML}-\mathrm{CP}$ and accelerated phase CML (CML-AP) resistant to or intolerant of prior therapy, including imatinib. The approval of nilotinib in CML-CP and CML-AP was based on the results of a pivotal phase II registration trial which demonstrated significant efficacy and tolerability in these patients. ${ }^{27-29}$ Nilotinib treatment is generally very well tolerated and the associated toxic effect may include myelosuppression, skin rashes, and biochemical abnormalities such as elevations of lipase, transaminase and bilirubin. Also hyperglycemia is commonly observed, particularly in patients with latent or overt diabetes. However, the cases of clinically relevant pancreatic and liver toxicities are really sporadic. Also effects on QT prolongation were minimal and of no clinical relevance. ${ }^{27-29}$

Finally, to overcome imatinib resistance and to further improve the percentage of good responders, two different strategies can presently be envisaged. The first is to treat more intensively patients already at diagnosis, in order to accelerate responses and to hamper resistance to develop. The second is to react as soon as possible when signs of a lower degree of sensitivity to imatinib therapy become evident, like a slower clearance of the $\mathrm{BCR} / \mathrm{ABL}$ transcripts in the peripheral blood verified by RQ PCR. The first strategy can be accomplished by increasing imatinib dosage to $800 \mathrm{mg}$ daily or by already the more powerful second generation TKIs using as frontline therapy, such as dasatinib and nilotinib, that have already proved to be highly effective as second line therapy in (and are approved for) imatinib resistant cases and show an acceptable degree of toxicity. This strategy is presently being investigated in several ongoing clinical protocols designed for all or for specific groups of patients, like the 'Sokal's high' cases. ${ }^{30}$ The first data derived from these studies, still very preliminary, seem encouraging in terms of CCyR and major molecular remission rates, but the risk may be to over treat the majority of the patients who can respond optimally to $400 \mathrm{mg}$ imatinib daily, with all the related problems in terms of short-term and long-term effects, that in the case of the new TKIs nobody knows exactly. Finally, from a theoretical point of view, if resistance is not an ongoing process, but rather a pre-established characteristic of some $\mathrm{Ph}$-positive cells already present at diagnosis, the real advantage in terms of final outcome with respect to the traditional sequential therapy with imatinib as first line therapy and a second generation TKI as second line therapy awaits to be verified. In contrast, the major risk of the second strategy derives from the fact that it has recently been demonstrated that compound mutants ( 2 or 3 BCR-ABL mutations in the same molecule) may arise by using different TKIs sequentially. ${ }^{31}$ This finding outlines the potential hazards of sequential kinase inhibitor therapy to overcome resistance and suggests a role for a combination therapy with different ABL kinase inhibitors in the same therapeutic scheme, used sequentially or simultaneously. Trials aiming to test the possible benefit of "combination therapies with TKIs" are planned.

\section{Resumo}

Respostas impressionantes e boa tolerância transformaram o imatinibe no "padrão ouro" de tratamento de primeira linha na LMC em fase crônica precoce. Evolução favorável em mais de 2/3 dos pacientes com LMC é obtida com dose standard de $400 \mathrm{mg}$ por dia. Critérios para estabelecer falha de tratamento e resposta "subótima" têm sido definidos. Guidelines têm sugerido que o escalonamento da dose do imatinibe possa melhorar a resposta em subgrupo de pacientes. Entretanto, a despeito de todos os esforços para otimizar a resposta ao imatinibe, casos de resistência realmente existem. Para os casos de intolerância ou resistência ao imatinibe, inibidores potentes de segunda geração foram desenvolvidos e registrados (nilotinibe e dasatinibe). Além disto, terapêutica sequencial de inibidores podem ultrapassar a resistência, e a terapia combinada usada sequencialmente ou simultaneamente pode ser usada como estratégia futura. Rev. Bras. Hematol. Hemoter. 2009;31(Supl. 2):57-60.

Palavras-chave: Leucemia mieloide crônica; inibidores de tirosinoquinases; resistência e intolerância.

\section{References}

1. Druker BJ, Guilhot F, O'Brien SG, Gathmann I, Kantarjian H, Gattermann N, et al. Five-year follow-up of patients receiving imatinib for chronic myeloid leukemia. N Engl J Med. 2006;355(23):2408-17.

2. O'Brien S., Guilhot F, Goldman JM, et al. International randomized study of Interferon versus STI571 (IRIS) 7-Year Follow-up. Blood (ASH Annual Meeting Abstracts), Nov 2008; 112

3. Baccarani M, Saglio G, Goldman J, Hochhaus A, Simonsson B, Appelbaum F, et al. Evolving concepts in the management of chronic myeloid leukemia: recommendations from an expert panel on behalf of the European LeukemiaNet. Blood. 2006;108(6): 1809-20.

4. Picard S, Titier K, Etienne G, Teilhet E, Ducint D, Bernard MA, et al. Trough imatinib plasma levels are associated with both cytogenetic and molecular responses to standard-dose imatinib in chronic myeloid leukemia. Blood. 2007;109(8):3496-9.

5. White D, Saunders V, Grigg A, Arthur C, Filshie R, Leahy MF, et al. Measurement of in vivo BCR-ABL kinase inhibition to monitor imatinib-induced target blockade and predict response in chronic myeloid leukemia. J Clin Oncol. 2007;25(28):4445-51. 
6. Larson RA, Druker BJ, Guilhot F, O'Brien SG, Riviere GJ, Krahnke $\mathrm{T}$, et al. Imatinib pharmacokinetics and its correlation with response and safety inchronic-phase chronic Imatinib pharmacokinetics and its correlation with response and safety in chronic-phase chronic myeloid leukemia: a subanalysis of the IRIS study. Blood. 2008;111(8):4022-8.

7. Kantarjian HM, Larson RA, Guilhot F, O'Brien SG, Mone M, et al; International Randomized Study of Interferon and STI571 (IRIS) Investigators. Efficacy of imatinib dose escalation in patients with chronic myeloid leukemia in chronic phase. Cancer. 2009;115(3):551-60.

8. Cortes J, Talpaz M, O'Brien S, et al. High-Dose Imatinib mesylate treatment in patients (pts) with previously untreated early chronic phase (CP) Chronic Myeloid Leukemia (CML). Blood (ASH Annual Meeting Abstracts) 2004; 104: 999.

9. Cortes J, Giles F, Salvado A, et al. Interim analysis of a multicenter trial of High Dose (HD) Imatinib in newly diagnosed early chronic phase (CP) patients (pt) with Chronic Myeloid Leukemia (CML). Blood (ASH Annual Meeting Abstracts), Nov 2005; 106: 1085.

10. Baccarani M, Rosti G, Castagnetti F, Haznedaroglu I, Porkka K, Abruzzese E, et al. Comparison of imatinib $400 \mathrm{mg}$ and $800 \mathrm{mg}$ daily in the front-line treatment of high-risk, Philadelphia-positive chronic myeloid leukemia: a European LeukemiaNet Study. Blood. 2009;113(19):4497-504.

11. Apperley JF. Part I: mechanisms of resistance to imatinib in chronic myeloid leukaemia. Lancet Oncol. 2007;8(11):1018-29.

12. Deininger M. Resistance to imatinib: mechanisms and management. J Natl Compr Canc Netw. 2005;3(6):757-68.

13. O'Hare T, Eide CA, Deininger MW. Bcr-Abl kinase domain mutations, drug resistance, and the road to a cure for chronic myeloid leukemia. Blood. 2007;110(7):2242-9.

14. Jabbour E, Cortes JE, Giles FJ, O'Brien S, Kantarjian HM. Current and emerging treatment options in chronic myeloid leukemia. Cancer. 2007;109(11):2171-81.

15. O'Hare T, Walters DK, Stoffregen EP, Jia T, Manley PW, Mestan $\mathrm{J}$, et al. In vitro activity of Bcr-Abl inhibitors AMN107 and BMS354825 against clinically relevant imatinib-resistant Abl kinase domain mutants. Cancer Res. 2005;65(11):4500-5.

16. Lombardo LJ, Lee FY, Chen P, Norris D, Barrish JC, Behnia K, et al. Discovery of N-(2-chloro-6-methyl- phenyl)-2-(6-(4-(2hydroxyethyl)- piperazin-1-yl)-2-methylpyrimidin-4ylamino)thiazole-5-carboxamide (BMS-354825), a dual Src/Abl kinase inhibitor with potent antitumor activity in preclinical assays. J Med Chem. 2004;47(27):6658-61.

17. Wu J, Meng F, Lu H, Kong L, Bornmann W, Peng Z, et al. Lyn regulates $\mathrm{BCR}-\mathrm{ABL}$ and $\mathrm{Gab} 2$ tyrosine phosphorylation and $\mathrm{c}-\mathrm{Cb}$ protein stability in imatinib-resistant chronic myelogenous leukemia cells. Blood. 2008;111(7):3821-9.

18. Wu J, Meng F, Kong LY, Peng Z, Ying Y, Bornmann WG, et al. Association between imatinib-resistant BCR-ABL mutationnegative leukemia and persistent activation of LYN kinase. J Natl Cancer Inst. 2008;100(13):926-39.

19. Talpaz M, Shah NP, Kantarjian H, Donato N, Nicoll J, Paquette R, et al. Dasatinib in imatinib-resistant Philadelphia chromosomepositive leukemias. N Engl J Med. 2006;354(24):2531-41.

20. Hochhaus A, Kantarjian HM, Baccarani M, Lipton JH, Apperley JF, Druker BJ, et al. Dasatinib induces notable hematologic and cytogenetic responses in chronic-phase chronic myeloid leukemia after failure of imatinib therapy. Blood. 2007;109(6):2303-9.

21. Cortes J, Rousselot P, Kim DW, Ritchie E, Hamerschlak N, Coutre $\mathrm{S}$, et al. Dasatinib induces complete hematologic and cytogenetic responses in patients with imatinib-resistant or -intolerant chronic myeloid leukemia in blast crisis. Blood. 2007;109(8):3207-13.
22. Guilhot F, Apperley J, Kim DW, Bullorsky EO, Baccarani M, Roboz GJ, et al. Dasatinib induces significant hematologic and cytogenetic responses in patients with imatinib-resistant or intolerant chronic myeloid leukemia in accelerated phase. Blood. 2007;109(10):4143-50.

23. Shah NP, Kantarjian HM, Kim DW, Réa D, Dorlhiac-Llacer PE, Milone $\mathrm{JH}$, et al. Intermittent target inhibition with dasatinib 100 mg once daily preserves efficacy and improves tolerability in imatinib-resistant and -intolerant chronic-phase chronic myeloid leukemia. J Clin Oncol. 2008;26(19):3204-12.

24. Golemovic M, Verstovsek S, Giles F, Cortes J, Manshouri T, Manley PW, et al. AMN107, a novel aminopyrimidine inhibitor of Bcr$\mathrm{Abl}$, has in vitro activity against imatinib-resistant chronic myeloid leukemia. Clin Cancer Res. 2005;11(13):4941-7.

25. Weisberg E, Manley PW, Breitenstein W, Brüggen J, Cowan-Jacob SW, Ray A, et al. Characterization of AMN107, a selective inhibitor of native and mutant Bcr-Abl. Cancer Cell. 2005;7(2):129-41.

26. Ray A, Cowan-Jacob SW, Manley PW, Mestan J, Griffin JD. Identification of BCR-ABL point mutations conferring resistance to the Abl kinase inhibitor AMN107 (nilotinib) by a random mutagenesis study. Blood. 2007;109(11):5011-5.

27. Kantarjian HM, Giles F, Gattermann N, Bhalla K, Alimena G, Palandri F, et al. Nilotinib (formerly AMN107), a highly selective BCR-ABL tyrosine kinase inhibitor, is effective in patients with Philadelphia chromosome-positive chronic myelogenous leukemia in chronic phase following imatinib resistance and intolerance. Blood. 2007;110(10):3540-6.

28. Giles FJ, Larson RA, Kantarjian H, et al. Nilotinib in patients (pts) with philadelphia chromosome-positive $(\mathrm{ph}+)$ chronic myelogenous leukemia in blast crisis (CML-BC) who are resistant or intolerant to imatinib. Blood, ASH Annual Meeting Proceedings 110: Abstract 1025., 2007

29. le Coutre P, Ottmann OG, Giles F, Kim DW, Cortes J, Gattermann $\mathrm{N}$, et al. Nilotinib (formerly AMN107), a highly selective BCRABL tyrosine kinase inhibitor, is active in patients with imatinibresistant or -intolerant accelerated-phase chronic myelogenous leukemia. Blood. 2008;111(4):1834-9.

30. Baccarani M, Rosti G, Castagnetti F, Haznedaroglu I, Porkka K, Abruzzese E, et al. Comparison of imatinib $400 \mathrm{mg}$ and $800 \mathrm{mg}$ daily in the front-line treatment of high-risk, Philadelphia-positive chronic myeloid leukemia: a European LeukemiaNet Study. Blood. 2009;113(19):4497-504.

31. Shah NP, Skaggs BJ, Branford S, Hughes TP, Nicoll JM, Paquette $\mathrm{RL}$, et al. Sequential ABL kinase inhibitor therapy selects for compound drug-resistant BCR-ABL mutations with altered oncogenic potency. J Clin Invest. 2007;117(9):2562-9.

O tema apresentado foi proposto pela Organização do $8^{\circ}$ Simpósio da Associação Ítalo-Brasileira de Hematologia, realizado durante o XIII Congresso de Transplante de Medula Óssea.

Publicado após concordância do editor.

Conflito de interesse: sem conflito de interesse

Recebido: 16/07/2009

Aceito: 16/07/2009 